\section{Metabolic syndrome: A case report}

\author{
Dragan Klaric ${ }^{1}$, Marta Martinis ${ }^{1 *}$ and Marta Klaric ${ }^{2}$ \\ 1'Department of Nephrology and Dialysis, General Hospital Zadar, Croatia \\ ${ }^{2}$ School of Medicine, Rijeka, Croatia
}

\section{Abstract}

Metabolic syndrome composed of abdominal obesity, atherogenic dyslipidemia, raised blood pressure, insulin resistance and/or glucose intolerance, proinflammatory state and prothrombotic state is a complex multisystem disorder. It is well known that patients with metabolic syndrome have increased cardiovascular risk and risk of developing diabetes type II. But besides these well known risk states, there are other conditions such as polycystic ovary syndrome, fatty liver, cholesterol gallstones, asthma, sleep disturbances and some forms of cancer associated with a metabolic syndrome. In this case report we will present a patient who developed many of these conditions related to the metabolic syndrome and will highlight the novel efforts regarding to the lifestyle changes, primarily weight loss.

\section{More Information}

*Address for Correspondence: Marta Martinis, Department of Nephrology and Dialysis, General Hospital Zadar, Croatia, Tel: +385 99720 9695; Email: martazut@gmail.com

Submitted: August 28, 2021

Approved: September 07, 2021

Published: September 08, 2021

How to cite this article: Klaric D, Martinis $M$, Klaric M. Metabolic syndrome: A case report. Ann Clin Endocrinol Metabol. 2021; 5: 031-035.

DOI: 10.29328/journal.acem.1001022

Copyright: @ 2021 Klaric D, et al. This is an open access article distributed under the Creative Commons Attribution License, which permits unrestricted use, distribution, and reproduction in any medium, provided the original work is properly cited.

\section{Check for updates \\ OPEN ACCESS}

\section{Introduction}

It is well known that the metabolic syndrome, also called the insulin resistance syndrome, is composed of several complex metabolic disorders. Despite some disagreements regarding diagnostic criteria, it is established that the metabolic syndrome has following components: abdominal obesity, atherogenic dyslipidemia, raised blood pressure, insulin resistance and/or glucose intolerance, proinflammatory state and prothrombotic state [1-3]. In 1988 Raven named these metabolic disorders as Syndrome $X$ giving it for the first time clinical importance. During 1989 Kaplan started to use the term The deadly quartet, while others later started to use the term The insulin resistance syndrome. Nowadays, the term Metabolic syndrome is widely accepted and is considered to be the most useful in clinical practice $[4,5]$.

Individuals with metabolic syndrome have increased risk of development the cardiovascular disease and diabetes type II. But besides these well known risk conditions, these individuals can develop some other conditions such as polycystic ovary syndrome, fatty liver, cholesterol gallstones, asthma, sleep disturbances and some forms of cancer $[2,5]$.

In this case report we are going to present a patient who developed multiple complications within metabolic syndrome. Also, we will highlight some new efforts that have been made in the world and are especially focused on the dietary habit recommendations. Proper nutrition requires discipline from the patient but is the key factor in the management and prognosis of all components and complications of metabolic syndrome.

\section{Case report}

We present a 53 year old male patient who was diagnosed with nonalcoholic liver disease and metabolic syndrome at the age of 35 . Metabolic syndrome was present with all its components and complications and because of that we consider this patient a great example and review of disorders spectrum which can develop within and as a concrescence of this syndrome (Table 1).

From the anamnesis we have found out that in the childhood he has overcome rheumatic fever and besides nonalcoholic liver cirrhosis he has been diagnosed with type 2 diabetes, hypertension, hyperlipidemia, gastritis, colon polyps, Hashimoto thyroiditis, hyperparathyroidism, nephrolithiasis and severe sleep apnea.

From the family history we have found out that his father had type II diabetes, hyperlipidemia and hypertension.

\begin{tabular}{|c|c|c|}
\hline System & Comment & Procedure \\
\hline $\mathrm{CNS}^{*}$ & $\begin{array}{l}\text { Sleeping disorders, social } \\
\text { anxiety }\end{array}$ & Polysomnography, fundoscopy \\
\hline CVS $^{*}$ & $\begin{array}{l}\text { Hypertension, } \\
\text { atherosclerosis }\end{array}$ & BPM, fundoscopy \\
\hline $\mathrm{GIS}^{*}$ & $\begin{array}{l}\text { Nonalcoholic liver disease, } \\
\text { polypus in the cecum, } \\
\text { chronic gastritis, Barrett's } \\
\text { esophagitis }\end{array}$ & $\begin{array}{l}\text { Laboratory findings, liver biopsy, } \\
\text { abdominal ultrasound, fibroscan, } \\
\text { MSCT of the abdomen, } \\
\text { gastroscopy, colonoscopy }\end{array}$ \\
\hline Endocrine system & $\begin{array}{l}\mathrm{DM}^{*} \text { type II, } \\
\text { Hashimoto thyroiditis, } \\
\text { hyperparathyroidism, } \\
\text { hyperaldosteronism }\end{array}$ & $\begin{array}{l}\text { Laboratory findings, parathyroid } \\
\text { glands ultrasound, densitometry } \\
\text { thyroid ultrasound }\end{array}$ \\
\hline
\end{tabular}

*CNS: Central Nervous System; CVS: Cardiovascular System; BPM: Blood Pressure Measurement; GIS: Gastrointestinal System; DM: Diabetes Mellitus 
In the physical status we can find body weight of the patients $120 \mathrm{~kg}$, body height $184 \mathrm{~cm}$, waist circumference 113 $\mathrm{cm}$ and BMI (body mass index) 34.5. Arterial blood pressure is $160 / 90 \mathrm{mmHg}$. The abdomen is above the level of the chest, the liver is enlarged by up to $5 \mathrm{~cm}$ as well as the spleen with some difficulties during palpation. Other physical finding is unremarkable.

\section{Laboratory findings}

Glucose 7,7 mmol; HbA1c 9\%; ALT (Alanine aminotransferase) $134 \mathrm{U} / \mathrm{L} ;$ AST (Aspartate aminotransferase) $74 \mathrm{U} / \mathrm{L} ; \quad$ GGT (Gamma-glutamyltransferase) $127 \mathrm{U} / \mathrm{L}$; ALP (Alkaline phosphatase) $101 \mathrm{U} / \mathrm{L}$; PTH (Parathyroid hormone) 13,29 pmol/L; cholesterol 5,1 mmol/L; HDL (High-density lipoprotein) 0,74 mmol/L; LDL (Low-density lipoprotein) 3,581 mmol/L; Vitamin D3 (25-OH) $32 \mathrm{mmol} / \mathrm{L}$; P (Phosporus) 0,82 mmol/L; CRP (C-reaktive protein) 6,8 $\mathrm{mg} / \mathrm{L}$; TSH (Thyroid-stimulating hormone) 5,19 mlU/L, fT4 14,8 pmol/LCrC (Creatinine clearance) $151.1 \mathrm{ml} / \mathrm{min}$, Na $139 \mathrm{mmol} /$, K 3,4 mmol/L, Ca 2,39 mmol/L, proteinuria 0,26 $\mathrm{g} / 24 \mathrm{~h}, \mathrm{Ca}$ in the urine $17,32 \mathrm{mmol} / 24 \mathrm{~h}, \mathrm{P}$ in the urine 54 $\mathrm{mmol} / 24 \mathrm{~h}$, aldosterone $622 \mathrm{pmol} / \mathrm{L}$, rennin activity $0,9 \mathrm{mcg} /$ $\mathrm{L} / \mathrm{h}$, hepatitis markers negative.

\section{Diagnostic procedures}

Liver biopsy: Pathohistological findings of the liver tissue describe histologically severe disorder of the architecture. The portal spaces are enlarged with severe fibrosis and with medium abundant, mixed inflammatory infiltration which contains a lot of eosinophils. The piece meal necrosis is wieldy present. Also the epithelium damage of the bile ducts can be seen. From the portal spaces connective tissue is spread into the parenchyma and in several places surrounds regenerative liver nodules. Perivenular, perisinusoidal and pericellular fibrosis is widely expressed. Macrovesicular as well as microvesicular steatosis is widely expressed in the liver parenchyma also with some lipogranuloma. Besides the portal spaces plenty of ballooned cells filled with Mallory's hyaline are present, in some places surrounded with mononuclear inflammatory cells. There is also some portoportal and portocentral bridging necrosis. According to pathohistiological findings this is a chronic steatohepatitis that goes into the liver chirosis.

Abdominal ultrasound: The liver is normal sized with proper contours and reflective, shiny echostructure, without significant signs of focal lesion. Pancreas and spleen have normal morphology. In the right kidney parenchyma there is a smaller calcification.

FibroScan: Even though liver biopsy with pathohistological analysis is considered the gold standard for diagnosis of liver steatosis and fibrosis, status of the liver can be established by newer non-invasive methods such as FibroScan, Fibromax or ELF tests. In our diagnostic procedure we used FibroScan method which includes ultrasound B-mode imaging for the evaluation of liver steatosis and fibrosis. In this method the main parameters for the determination of liver fibrosis and steatosis are liver stfifness measurement and controlled attenuation parameter [6,7]. In our patient fibroscan showed nonalcoholic steatohepatitis with extremely high degree of fibrosis (median stiffness 25.4 Kpa, IQR 5.7 Kpa, IQR / med $22 \%)$.

MSCT of the abdomen after intravenous application of the contrast agent: The liver is normal sized with proper contours and normal intense of the parenchyma signaling without focal lesions. The gallbladder wall has normal morphology without intraluminal content. There is not seen dilatation of the bile ducts. The spleen is homogeneous and enlarged (diameter $15 \mathrm{~cm}$ ). Kidneys are normal sized with held parenchyma without dilatation of the canal system. Adrenal glands have normal morphology without focal lesions.

Gastroscopy: Chronic gastritis and esophageal mucosa damage in terms of Barrett's esophagitis.

Colonoscopy: Polypus in the bottom of the cecum was removed and the pathohistiologycal findings have not showed any malignant cells.

The eye fundus examination: Arteries of enhanced central reflex, hypertonicus gr I.

Thyroid ultrasound: Both thyroid lobes can be described. The right lobe measured 5, $3 \times 1,6 \times 1,8$ with hypoechoic echotexture and uneven rear contour. The left lobe measured $4.6 \times 1.6 \times 1.8 \mathrm{~cm}$ with hypoechogenic echostructure and uneven rear contur. In the upper third of the left lobe there is hypoechogenic areal measured $0.6 \times 0.3 \times 0.7 \mathrm{~cm}$ and hypoehogenic areal measured $0.4 \times 0.4 \times 0.4 \mathrm{~cm}$. Isthmus is $0,3 \mathrm{~cm}$ in the size.

Parathyroid glands ultrasound: There is no hyperplasia of parathyreoid glands.

Densitometry: Normal bone density without sings of pathological bone remodeling.

The center for sleep medicine, polysomnography: Obstructive sleep apnea, mixed apnea 16, central apnea 16, hypopnea 189 . Average oxygen saturation was $94 \%$, while the lowest recorded desaturation was $82 \%$, desaturation index was 28.3 / h.

\section{Discussion}

In this article we presented the patient with metabolic syndrome and a whole series of complications that goes with this multisistemic condition.

Our patient has been shown to have nonalcoholic fatty liver disease, chronic steatohepatitis that is developing into cirrhosis, confirmed by pathohistological findings. This is a 
clinical syndrome that involves simple steatosis, nonalcoholic steatohepatitis with or without liver fibrosis, liver cirrhosis and hepatocellular carcinoma [8-11].

Nonalcococholic fatty liver disease develops as a consequence of the metabolic syndrome components. More and more research suggests that this disease is not exclusively related to the liver itself and is most commonly associated with cardiovascular diseases, chronic kidney disease and type II diabetes. Also, more recently, there is an increasing number of studies investigating the association of nonalcoholic fatty liver disease and adenomatous colon polyps and colorectal cancer, endocrinopathies such as hypothyroidism and sleep apnea syndrome [1,8-11].

Obesity is one of the components of metabolic syndrome that carries a whole host of other complications. Central obesity is a more significant indicator of the risk of developing type II diabetes, dyslipidemia and cardiovascular disease than BMI (body mass index) itself $[8,9]$. Our patient was extremely obese with developed expected complications of such obesity, which is type II diabetes, arterial hypertension and hyperlipidemia, each condition poorly regulated and controlled due to lack of discipline and poor patient compliance. Despite the maximum correction of oral hypoglycemic therapy, diabetes was not well regulated. He did not adhere to a reductive diabetic and low fat diet and did nothing to reduce the body weight.

Hashimoto thireoiditis is monitored in the patient and under the substitution therapy with levothyroxine the thyroid hormone values are successfully maintained within the limits of the reference values. Ultrasonic examination of the thyroid gland revealed typical morphological changes within this autoimmune disease.

During the follow-up he did not develop any major complications of cardiovascular disease but chronic poorly regulated arterial hypertension in the future could lead to more serious consequences. Namely, it is known that modification of the life habits including body weight regulation, appropriate body activity, smoking cessation, healthy nutrition and successful treatment and control of comorbidities such as DM type II, dyslipidemia, and hypertension reduces the cardiovascular disease incidence [8-10,12].

A number of studies point to the association of nonalcoholic fatty liver disease with cardiovascular disease. A varies studies have shown that patients with nonalcoholic fatty liver disease have a certain degree of the endothelial dysfunction, left ventricular diastolic dysfunction and higher prevalence of atherosclerotic plaques compared to patients with a healthy liver. Research is conducted in the direction of proving potential direct active involvement of nonalcoholic liver disease in atherogenic processes [8,9,13-16].

It is not completely clear whether there is a direct involvement of this liver condition or is this condition consequence of mutual metabolic factors that also lead to the cardiovascular disease as well $[8,13]$.

Insulin resistance that is a key factor for the type II diabetes mellitus development seems to be also associated with an increased risk of colorectal cancer $[1,8]$. In their research Schoen, et al. [17] showed that fasting insulin values were not associated with the risk of colorectal cancer development as opposed to insulin values measured after 2 hours. In patients with increased values measured after 2 hours an increased risk of colorectal cancer has been observed [1]. Studies have shown that some of the insulin resistance factors such as insulin and insulin like growth factor 1 and 2 stimulate a development of column polyps that are considered to be precursors of colorectal cancer and their progression into the invasive adenocarcinoma. Also, newer studies are trying to connect the risk of colorectal neoplasia with nonalchocolic fatty liver disease $[1,8,18-20]$. Colonoscopy found a polypus in the bottom of the cecum in our patient. Given the above described, our patient had a number of risk factors that favor the development of colon polyps and increase the risk of colorectal cancer development.

Despite the elevated values of PTH (excluding the last controlled value which was in the physiological range), we did not find any signs of primary hyperparathyroidism or paraneoplastic disease. Given the PTH and bilateral nephrolithiasis, we often repeated 24-hour calciuria which was always extremely high (20.4 mmol / 24 h, $17.32 \mathrm{mmol} /$ $24 \mathrm{~h} 13.24 \mathrm{mml} / 24 \mathrm{~h}$ ), followed by glomerular hyperfiltration without albuminuria.

The values of vitamin D $25(\mathrm{OH})$ were lower than the recommended (reduced synthesis within heavy hepatic fibrosis).

We believe that the increase in PTH was a "reflexive" response to increased 24-hour urinary calcium loss with lower vitamin D levels and possible polyglandular disorder within the metabolic syndrome. After the thiazide diuretic and small doses of vitamin D administration, a decrease in total calciuria from $20.4 \mathrm{mmol} / 24 \mathrm{hr}$ to $9 \mathrm{mmol} / 24$ with normal PTH levels was achieved. There were no morphological and biochemical changes on the bones.

Within the multiglandular insufficiency long term hypochalemia was observed in more detailed and hyperaldosteronism was suspected. Primary hyperaldosteronism was excluded, and long-term hypochalemia is a consequence of hyperaldosteronism within the liver disease. As the serum potassium correction did not improve by adequate intake of potassium-rich food and potassium preparations, small doses of spironolactone were introduced in the therapy.

As a part of metabolic syndrome, and because of the obesity, obstructive sleep apnea syndrome (OSAS) is a common 
condition $[21,22]$. OSAS is a clinical condition characterized by recurrent episodes of complete or partial obstruction of the upper respiratory tract resulting in the increased negative intrathoracic pressure, sleep fragmentation and intermittent hypoxia during sleep. In patients with the metabolic syndrome the prevalence of moderate to severe OSAS is high and is independently associated with elevated glucose and lipid levels, inflammatory markers, arterial stiffness and atherosclerosis. OSAS increases the cardiometabolic risk associated with obesity and metabolic syndrome. Recent studies link OSAS with the risk of fatty liver disease, nonalcoholic fatty liver disease and cirrhosis development [2329]. Due to obesity this patient developed severe obstructive sleep apnea which needed a medical treatment in the center for sleep medicine.

During the night he had a subjective poor sleeping quality with severe snoring, observed breathing pauses during the sleep and a sense of fatigue throughout the day. Due to above mentioned difficulties and treatment findings it is advised to initiate CPAP (Continuous positive airway pressure) treatment.

Finally, despite all described complications and comorbidities a chronic kidney disease has not been developed because the renal function is still compensated by the hyperfiltration. During the time we expect a decline in the renal function.

Although all discussed complications of metabolic syndrome present in our patients are all well known, metabolic syndrome still stays a big public health problem because its management is not simple at all. Nowadays, efforts are oriented towards changing of lifestyle habits, primarily fighting against the obesity and education of this group of patients. American Diabetes Association published Standards of Medical Care in Diabetes-2021, guidelines for nutritional and lifestyle recommendations in treatment od type 2 diabetes, that is typically seen as a part of metabolic syndrome. This guideline offers protocols and approaches for clinicians to guide weight loss in their patients (dietary prescription, lifestyle counselling, cognitive behaviour therapy). Our patient is the example of the importance of individual approach because changing of the lifestyle habits is often a long-term and complicated process [29,30].

In their overview, Silva Figueiredo, et al. focused on nutraceuticals and dietary supplements that could be beneficial in progression of the metabolic syndrome and its complications. Food rich in polyphenols and phenolic compounds added to vitamin $\mathrm{D}$, fruits and vegetables can reduce pro-inflammatory state present in the metabolic syndrome and cardiovascular risk. Also, the consumption of fish oil with EPA and DHA can improve the lipid profile and endothelial function. Introduction of such beneficial nutraceuticals should be further investigated for the purpose of potential addition to standard treatment options [31].
Some newer studies highlight the Mediterranean diet to have beneficial and protective effect on the different components of metabolic syndrome. Polyphenols contained in Mediterranean diet components such as olive oil, red wine and nuts seems to be beneficial in preventing and delaying the metabolic syndrome and its complications. It seems that the polyphenols contained in Mediterranean diet can reduce inflammatory and oxidative stress markers, improve lipid profile, insulin sensiticity and endothelial function. New studies are focused on benefit of these nutrients when added to standard medication therapy $[32,33]$.

\section{Conclusion}

The purpose of this article was to present a variety of diseases that developed in this patient and all of them were described in the literature as potential complications of metabolic syndrome. Individual approach is very important in the treatment of these patients especially because patient compliance is often poor. Obesity, improper nutrition, and lack of exercise are recognized as one of the most important factors in the development of metabolic syndrome. Modification of the life habits and psychological support are crucial and as important as successful medical treatment. Further investigation should be directed in finding the best way of nutrition modification in this group of patients to prevent multiple complications that are well known.

\section{References}

1. Giovannucci E. Metabolic syndrome, hyperinsulinemia, and colon cancer: a review. Am J Clin Nutr. 2007; 86: 836-842.

PubMed: https://pubmed.ncbi.nlm.nih.gov/18265477/

2. Grundy SM, Brewer HB Jr, Cleeman JI, Smith Jr SC, Lenfant C, et al. Definition of metabolic syndrome: report of the National Heart, Lung, and Blood Institute/American Heart Association conference on scientific issuesrelated todefinition. ArteriosclerThrombVascBiol.2004;24:13-18. PubMed: https://pubmed.ncbi.nlm.nih.gov/14766739/

3. Rochlani Y, Pothineni NV, Kovelamudi S, Mehta JL. Metabolic syndrome: pathophysiology, management, and modulation by natural compounds. Ther Adv Cardiovasc Dis. 2017; 11: 215-225. PubMed: https://pubmed.ncbi.nlm.nih.gov/28639538/

4. Gami AS, Witt BJ, Howard DE, Erwin PJ, Gami LA, et al. Metabolic syndrome and risk of incident cardiovascular events and death: a systematic review and meta-analysis of longitudinal studies. J Am Coll Cardiol. 2007; 49: 403-414

PubMed: https://pubmed.ncbi.nlm.nih.gov/17258085/

5. Alberti KG, Zimmet P, Shaw J. Metabolic syndrome--a new world-wide definition. A Consensus Statement from the International Diabetes Federation. Diabet Med. 2006; 23: 469-480.

PubMed: https://pubmed.ncbi.nlm.nih.gov/16681555/

6. Day JW, Rosenberg WM. The enhanced liver fibrosis (ELF) test in diagnosis and management of liver fibrosis. $\mathrm{Br} \mathrm{J}$ Hosp Med (Lond) 2018; 79: 694-699.

PubMed: https://pubmed.ncbi.nlm.nih.gov/30526098/

7. Oeda S, Tanaka K, Oshima A, Matsumoto Y, Sueoka E, et al. Diagnostic Accuracy of FibroScan and Factors Affecting Measurements. Diagnostics (Basel) 2020; 10: 940.

PubMed: https://pubmed.ncbi.nlm.nih.gov/33198092/ 
8. Mikolasevic I, Milic S, Turk Wensveen T, Grgic I, Jakopcic V. et al. Nonalcoholic fatty liver disease - A multisystem disease? World J Gastroenterol. 2016; 22: 9488-9505.

PubMed: https://pubmed.ncbi.nlm.nih.gov/27920470/

9. Fotbolcu $\mathrm{H}$, Zorlu E. Nonalcoholic fatty liver disease as a multi-systemic disease. World J Gastroenterol. 2016; 22: 4079-4090. PubMed: https://pubmed.ncbi.nlm.nih.gov/27122660/

10. Younossi Z, Tacke F, Arrese M, Sharma BC, Mostafa I, et al. Globa Perspectives on Nonalcoholic Fatty Liver Disease and Nonalcoholic Steatohepatitis. Hepatology 2018; 69: 2672-2682.

PubMed: https://pubmed.ncbi.nlm.nih.gov/30179269/

11. Stefan N, Häring HU, Cusi K. Non-alcoholic fatty liver disease: causes, diagnosis, cardiometabolic consequences, and treatment strategies. Lancet Diabetes Endocrinol. 2019; 7: 313-324.

PubMed: https://pubmed.ncbi.nlm.nih.gov/30174213/

12. Byrne CD, Targher G. NAFLD: A multisystem disease. J Hepatol. 2015; 62: 47-64.

PubMed: https://pubmed.ncbi.nlm.nih.gov/25920090/

13. Targher G, Day CP, Bonora E. Risk of cardiovascular disease in patients with nonalcoholic fatty liver disease. N Engl J Med. 2010; 363: 1341-1350.

PubMed: https://pubmed.ncbi.nlm.nih.gov/20879883/

14. Han E, Lee YH, Kim YD, Kim BK, Park JY, et al. Nonalcoholic Fatty Liver Disease and Sarcopenia Are Independently Associated With Cardiovascular Risk. Am J Gastroenterol. 2020; 115: 584-595. PubMed: https://pubmed.ncbi.nlm.nih.gov/32141917/

15. Mantovani A, Scorletti E, Mosca A, Alisi A, Byrne CD, et al Complications, morbidity and mortality of nonalcoholic fatty liver disease. Metabolism. 2020; 111: 154170.

PubMed: https://pubmed.ncbi.nlm.nih.gov/32006558/

16. Targher G, Bertolini L, Padovani R. Prevalence of nonalcoholic fatty liver disease and its association with cardiovascular disease among type 2 diabetic patients. Diabetes Care. 2007; 30: 1212-1218.

PubMed: https://pubmed.ncbi.nlm.nih.gov/17277038/

17. Schoen RE, Tangen CM, Kuller LH, Burke GL, Cushman M, et al. Increased blood glucose and insulin, body size, and incident colorectal cancer. J Natl Cancer Inst. 1999; 91: 1147-1154.

PubMed: https://pubmed.ncbi.nlm.nih.gov/10393723/

18. Lin $\mathrm{XF}$, Shi $\mathrm{KQ}$, You $\mathrm{J}$ i sur. Increased risk of colorectal malignant neoplasm in patients with nonalcoholic fatty liver disease: a large study. Mol Biol Rep. 2014; 41: 2989-2997.

PubMed: https://pubmed.ncbi.nlm.nih.gov/24449368/

19. Katsiki N, Mikhailidis DP, Mantzoros C. Non-alcoholic fatty liver disease and colorectal cancer: A marker of risk or common causation? Metabolism. 2018; 87: 10-13.

PubMed: https://pubmed.ncbi.nlm.nih.gov/30172755/

20. Ahn JS, Sinn DH, Min YW. Non-alcoholic fatty liver diseases and risk of colorectal neoplasia. Aliment Pharmacol Ther. 2017; 45: 345-353. PubMed: https://pubmed.ncbi.nlm.nih.gov/27859470/

21. Drager LF, Togeiro SM, Polotsky VY. Obstructive sleep spnea: a cardiometabolic risk in obesity and the metabolic syndrome. J Am Coll
Cardiol. 2013; 62: 569-576

PubMed: https://pubmed.ncbi.nlm.nih.gov/23770180/

22. Resta O, Foschino-Barbaro MP, Legari G, Talamo S, Bonfitto P, et al Sleep-related breathing disorders, loud snoring and excessive daytime sleepiness in obese subjects. Int J Obes Relat Metab Disord. 2001; 25: 669-675.

PubMed: https://pubmed.ncbi.nlm.nih.gov/11360149/

23. Reichmuth KJ, Austin D, Skatrud JB, Young T. Association of sleep apnea and type II diabetes: a population-based study. Am J Respir Crit Care Med. 2005; 172: 1590-1595.

PubMed: https://pubmed.ncbi.nlm.nih.gov/16192452/

24. Lee JY, Kim CW, Lee KC, Lee JH, Kang SH, et al. Effect of Intermittent Hypoxia on Metabolic Syndrome and Insulin Resistance in the General Male Population. Medicina (Kaunas). 2021; 57: 668.

PubMed: https://pubmed.ncbi.nlm.nih.gov/34209501/

25. Corey KE, Misdraji J, Gelrud L, King LY, Zheng H, et al. Obstructive sleep apnea is associated with nonalcoholic steatohepatitis and advanced liver histology. Dig Dis Sci. 2015; 60: 2523-2528.

PubMed: https://www.ncbi.nlm.nih.gov/pmc/articles/PMC4499481/

26. Vgontzas AN, Bixler EO, Chrousos GP. Sleep apnea is a manifestation of the metabolic syndrome. Sleep Med Rev. 2005; 9: 211-224. PubMed: https://pubmed.ncbi.nlm.nih.gov/15893251/

27. Chung GE, Cho EJ, Yoo JJ, Chang Y, Cho Y, et al. Nonalcoholic fatty liver disease is associated with the development of obstructive sleep apnea. Sci Rep. 2021; 11: 13473.

28. Sharma SK, Agrawal S, Damodaran D. CPAP for the metabolic syndrome in patients with obstructive sleep apnea. N Engl J Med. 2011; 365: 2277-2286

PubMed: https://pubmed.ncbi.nIm.nih.gov/22168642/

29. Petroni ML, Brodosi L, Marchignoli F, Sasdelli AS, Caraceni $P$, et al. Nutrition in Patients with Type 2 Diabetes: Present Knowledge and Remaining Challenges. Nutrients. 2021; 13: 2748.

30. American Diabetes Association. 8. Obesity management for the treatment of type 2 diabetes: Standards of medical care in Diabetes-2021. Diabetes Care. 2021; 44: 100-110. PubMed: https://pubmed.ncbi.nlm.nih.gov/33298419/

31. Silva Figueiredo $P$, Inada AC, Ribeiro Fernandes $M$, et al. An Overview of Novel Dietary Supplements and Food Ingredients in Patients with Metabolic Syndrome and Non-Alcoholic Fatty Liver Disease. Molecules. 2018; 23: 877.

PubMed: https://pubmed.ncbi.nlm.nih.gov/29641459/

32. Finicelli M, Squillaro $T$, Di Cristo $F$, Di Salle A, Melone MAB, et al. Metabolic syndrome, Mediterranean diet, and polyphenols: Evidence and perspectives. J Cell Physiol. 2019; 234: 5807-5826.

PubMed: https://pubmed.ncbi.nlm.nih.gov/30317573/

33. Ditano-Vázquez P, Torres-Peña JD, Galeano-Valle F, Pérez-Caballero Al, Demelo-Rodríguez P, et al. The Fluid Aspect of the Mediterranean Diet in the Prevention and Management of Cardiovascular Disease and Diabetes: The Role of Polyphenol Content in Moderate Consumption of Wine and Olive Oil. Nutrients. 2019; 11: 2833. PubMed: https://pubmed.ncbi.nlm.nih.gov/31752333/ 